\title{
A COMPARTIVE STUDY ON TWO DIFFERENT EVAPORATIVE COOLING SYSTEMS FOR PRODUCTING CUCUMBER CROP UNDER HOT-HUMID SUMMER CONDITIONS
}

Abdellatif, S. M. : M. M. M. Ibrahim and M. M. H. Ellithy

Agric. Eng. Dept., Fac. Agric., Mansoura Univ.

\begin{abstract}
The influence of greenhouse evaporative cooling systems (based on misting, and fan pads cooling systems) on the microclimatic conditions of greenhouse cucumber was studied and investigated in two fiberglass greenhouses combined with roof shading black net screen situated on the roof of the Agricultural Engineering Department, University of Mansoura. Measurements were executed during several days (122 days) in the hot summer of 2009; (G1) with a mist system operating $15 \mathrm{sec}$ every 15 min., (G2) with a pad-fan system. In order to compare between the cooling systems, air temperatures and relative humidity inside and outside the greenhouses were measured and recorded. Experimental data revealed that the pad-fan cooling system was able to keep the air temperature within the greenhouse at rather low levels. The internal air temperature stayed $8.0^{\circ} \mathrm{C}$ below outside, even during hot afternoons $\left(\mathrm{T}_{\mathrm{ao}}>35^{\circ} \mathrm{C}\right)$. Whereas, the evaporative cooling using mist system kept the greenhouse air temperature above the set point temperature by an average of $4.9^{\circ} \mathrm{C}$. Therefore, the internal air temperature stayed $4.2^{\circ} \mathrm{C}$ below outside. Due to the short length of the greenhouse $(8 \mathrm{~m})$, small temperature gradients $\left(2.9^{\circ} \mathrm{C}\right)$ were observed from wet pads to extracting fan. The cooling system using fan-pad system inside the greenhouse (G2) was on the average more efficient than the misting system inside the greenhouse (G1) by $22.5 \%$ due to the cooling operation period for the greenhouse (2) was longer than that for the greenhouse (1), accordingly, the water temperature of cooling system (2) was lower than that in misting system (G1). The total fresh yield of cucumber crop per square meter for greenhouse (G1) and greenhouse (G2) was 3.805 and $5.491 \mathrm{~kg} / \mathrm{m}^{2}$, respectively. Therefore, the greenhouse (G2) produced 1.686 $\mathrm{kg} / \mathrm{m}^{2}(44.31 \%)$ more than the greenhouse (G1).
\end{abstract}

\section{INTRODUCTION}

In Egypt, high air temperature $\left(\mathrm{T}>35^{\circ} \mathrm{C}\right)$ and vapour pressure deficit (VPD $>3 \mathrm{kPa}$ ) are currently observed in all greenhouses whether covered with plastic or fiberglass during hot summer season. These circumstances are responsible of the decrease in quantity and quality of protected cropping production. Various methods for ventilating and cooling the greenhouse microclimate may be used to keep more suitable conditions for plant growth. Natural ventilation is usually the first step due to its low cost and simplicity, but is generally insufficient for extracting the excess heat energy during hot summer days (Baille, 1999). Therefore, other cooling methods must be used in combination with ventilation. One of the most efficient solutions for alleviating the climatic conditions is to use evaporative cooling systems, based on the conversion of sensible heat into latent heat by means of evaporation process of water supplied directly into the greenhouse 
microclimate (mist or fog system, sprinklers) or through evaporative pads (wet pads). Evaporative cooling allows simultaneous lowering of temperature and vapour pressure deficit and can lead to greenhouse air temperature lower than the outside (Arbel et al., 1999 ; Willits, 1999). Its efficiency is higher in dry environments, but it also gives satisfactory results in humid coastal environments (Montero and Segal, 1993).

Air-cooling is desirable in many greenhouses in order to prevent plant stress and produce crops of marketable quality (Nelson, 1996). Various technical equipment can efficiently contribute to maintain greenhouse air temperature and relative humidity at acceptable levels during hot periods, but adequate models may be necessary to estimate the cooling loads and adequately manage such control equipment. Shading screens mounted externally or internally, may be used to reduce radiation inside the greenhouse but the effective temperature reduction is not really proportional to the shading rate. Externally mounted black polyethylene films were less than $50 \%$ effective in reducing heat energy and temperature gains compared with their commercially given values, while white shading cloths were only slightly more effective (Willits and Peet, 1993). Ventilation reduces greenhouse overheating, but it may even enhance the risk of water stress because it often increases plant transpiration. Kittas et al. (2001a) reported that, high ventilation rates were not, a priori, the best solution for alleviating crop stress in greenhouses during summer conditions. Evaporative cooling substantially improves the greenhouse climate. It can be executed by spraying water droplets in a naturally ventilated building (by low or high pressure fog systems) or by forcing ambient air through wet pads. Both produce a temperature drop with an absolute humidity rise in the greenhouse, which contributes to decrease the vapour pressure deficit and moderate the transpiration demand (Katsoulas et al., 2001).

The efficiency of fog systems is often limited by insufficient natural air convection, in the absence of wind, and by the risk of wetting the plants when water droplet evaporation is not complete. The main disadvantage of cooling pad systems is the creation of large temperature gradients inside the large greenhouse, from pads on one side to extracting fans on the opposite side. The amplitude of such gradients is affected by many factors, and only a numerical model can predict its value (Kittas et al., 2003). Five factors mainly affect the temperature distribution along the greenhouse; ventilation rate, crop transpiration, and soil evaporation, the latter being neglected in what follows; percentage of shading, water evaporation from the wet pads, and heat loss coefficient of the cover (Kittas et al., 2003). When cooling pad systems are used, they are often combined with roof shading. Kittas et al. (2001b) presented sensible and latent heat profiles observed along a large greenhouse, and, in order to explain their results, they proposed a model, which simulates the air temperature distribution inside the enclosure.

The aim of the present study was to compare between the mist and pad-fan cooling systems, and to propose a simple model including cucumber crop effect, and validate it against measurements in an experimental greenhouse. The model predicts the internal air temperature profiles and can be used to improve the commercial greenhouses. Measurements presented 
below were executed in an experimental fiberglass greenhouses cooled with two different evaporative cooling systems; (G1) with a mist system combined with roof shading screen and operating $15 \mathrm{sec}$. every $15 \mathrm{~min}$, (G2) with a pad-fan system combined with roof shading screen,

\section{MATERIALS AND METHODS}

\section{Experimental greenhouses and measurements}

The experiment was carried out during the hot summer growing season of 2009 in two identical gable-even-span single greenhouses located on roof of the Agricultural Engineering Department, University of Mansoura. The latitude, longitude angles and altitude of the Department, respectively, are $30.045^{\circ} \mathrm{N}, 31.365^{\circ} \mathrm{E}$, and $19.05 \mathrm{~m}$ above the sea level. Each one having a gross dimensions of $8 \mathrm{~m}$ long, $4 \mathrm{~m}$ wide, and $3.25 \mathrm{~m}$ high, with a net floor surface area of $32 \mathrm{~m}^{2}$. The rafter length of the greenhouse gable is $2.25 \mathrm{~m}$ and gable height is $1.02 \mathrm{~m}$, whilst the height of each side wall is $2 \mathrm{~m}$. The rafters were tilted $27^{\circ}$ with respect to horizontal plane in order to minimized the intensity of solar radiation on the roof of the greenhouse during summer months and alleviate the side effects of wind load. Moreover, with this inclined angle $\left(27^{\circ}\right)$ condensation will run down the underside and minimize dropping from the cover, which damaging crops and encouraging diseases. The two greenhouses (G1 and G2) are orientated in East-West direction and covered with $800 \mu$ thick corrugated fiberglass reinforced plastic (FRP). The greenhouse facility used in this research work during summer season of 2009 was covered with the ratio of cover surface area to the total greenhouse surface area of 2.685. In order to reduce the natural burden of heating from the solar radiation entering the greenhouse during daylight in summer month, and/or to increase the cooling effect of fan-pad cooling system, a shading black net screen $(50 \%)$ was used to cover the gable roof of the two greenhouses as shown in Fig. (1).

Reducing temperatures is one of the main problems facing greenhouse management during daylight in hot-humid summer conditions such as in Egypt. Ventilation is basically used to exchange air between the inside and outside of the greenhouse as a means of temperature, relative humidity, and carbon dioxide control. Exhaust fans should be sized to exchange the total volume of air in the greenhouse at a range of rates adjustable to the particular crop being grown. Ventilation requirements vary with the climatic conditions, the season, and the greenhouse usage. Therefore, the forced ventilation system (extracting fans) was used during this research work. One greenhouse (G1) was equipped by mist system consisted of four PVC water lines suspended on $2.23 \mathrm{~m}$ above the floor surface. The four main pipes were located at an equidistance of $75 \mathrm{~cm}$ between each two successive pipes. Eleven nozzles (7-10 liter/h) were uniformly alternative distributed with $50 \mathrm{~cm}$ nozzle spacing through and along of each PVC pipe $125 \mathrm{~mm}$ diameter) as shown in Fig. (2). The other greenhouse (G2) was equipped with a complete evaporative cooling system based on cooling pads and extracting fan. Ambient air was forced through $1.80 \mathrm{~m}^{2}$ face area of $10 \mathrm{~cm}$ thick cooling pads 
Abdellatif, S. M. et al.

situated on the middle of the western wall (side toward the prevailing winds). These corrugated cellulose pads permit $75 \mathrm{~m}^{3} / \mathrm{min} / \mathrm{m}^{2}$ air flow rate. After crossing the pads, air travels an $8 \mathrm{~m}$ distance before being extracted by one fan located on the opposite eastern side wall. The extracting fan generates a flow rate of about $8000 \mathrm{~m}^{3} / \mathrm{h}$ under $2.5 \mathrm{~mm}$ static pressure as shown in Fig. (3).
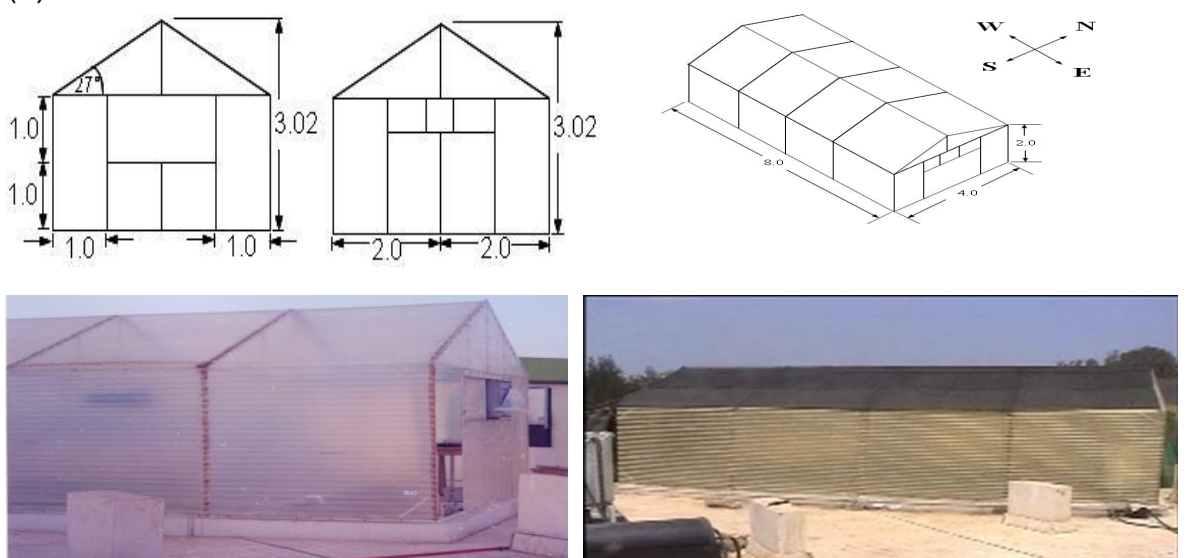

Fig. (1): Schematic diagram of the two experimental greenhouses.

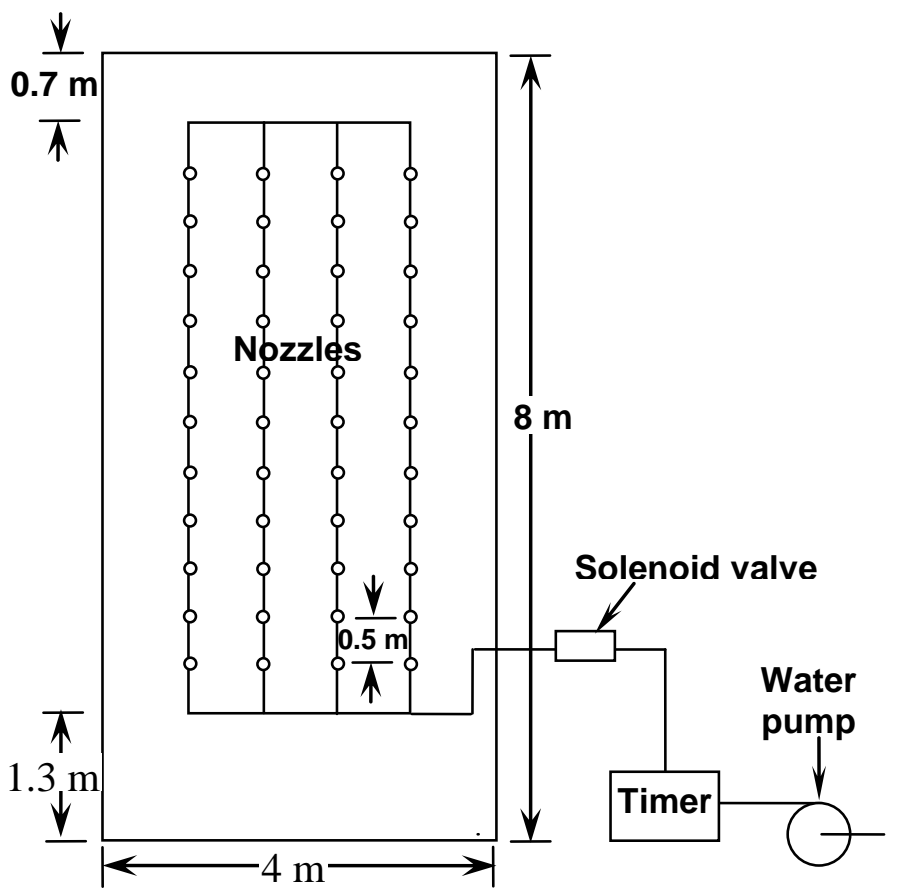

Fig. (2): Schematic diagram of misting system and distribution of nozzles inside the greenhouse. 

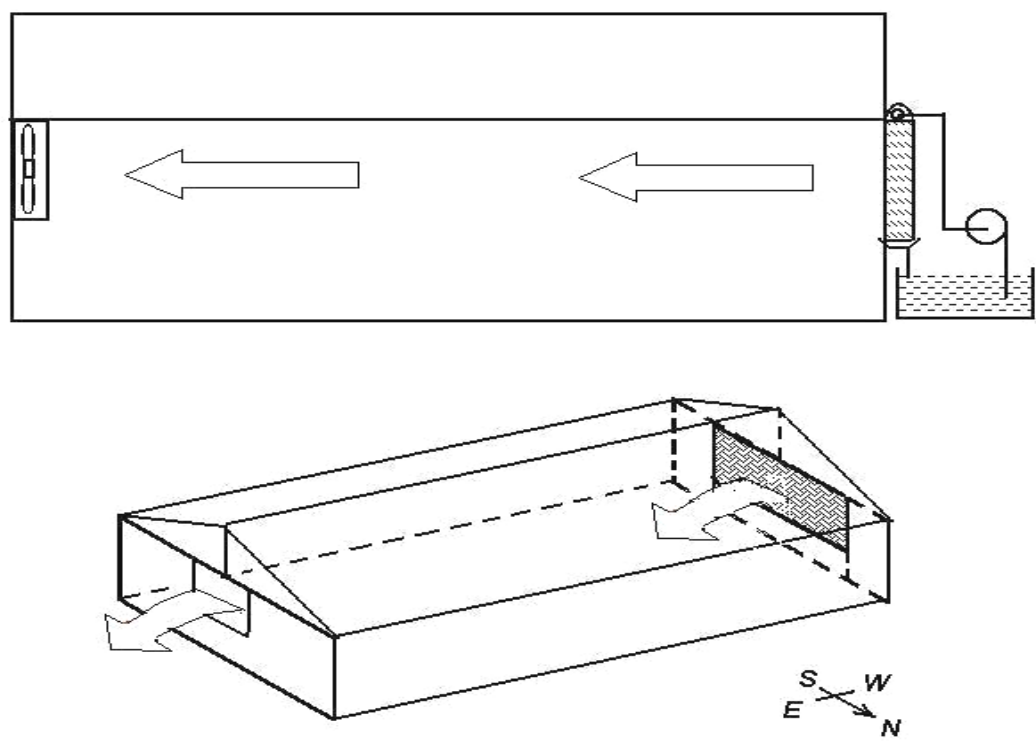

Fig. (3): Diagram of ventilation and cooling systems.(Fan and pad system)

The pots system was used as an agricultural system for protected cropping (cucumber crop) during the experimental period. Each greenhouse was equipped by 60 plastic pots $(30 \mathrm{~cm}$ high and $18 \mathrm{~cm}$ diameter). These pots contained a mixture of three different types of soil (clay soil, pure yellow sand, and Irish peat moss) with ratio of 1:1:1. They were uniformly distributed inside the two greenhouses in five rows (each one had twelve pots).

Two different irrigation systems were used inside the two greenhouses for watering pots of cucumber crop (drip irrigation and misting irrigation systems). Twelve drippers (long-bath GR 4 liter/hr discharge) were uniformly alternative distributed with $48 \mathrm{~cm}$ dripper spacing throughout each row of plants inside the greenhouse 2 (G2). Whereas, the water dropping from the misting system was used to watering the pots of cucumber crop inside the greenhouse 1 (G1). One hundred and thirty cucumber seeds (Beit Alfa GH, George Spirou Co., Greece) were directly planted in the pots on $26^{\text {th }}$ April 2009. After ten days the cucumber plants started to rise up in the pots with germination ratio of $96.7 \%$.

\section{Measurements}

Dry-bulb and wet-bulb air temperatures were measured and recorded at three different locations inside the greenhouse 1 ; the first one just next to the cooling pads (cold air just leaving the pads), the second located in the middle (mid-way down stream), and the third one just prior to the extracting 


\section{Abdellatif, S. M. et al.}

fan. Whereas, inside the greenhouse 2; the first one just at the opining air, the second located in the middle (mid-way down stream), and the third one just prior to the extracting fan. The temperatures probes were thermocouple type $\mathrm{K}$ with accuracy of $\pm 0.2^{\circ} \mathrm{C}$. The twelve thermocouples were connected to a 12 channel data-logger (Digi-Sense Scanning Thermometer Type, ColeParmer, USA) was used for recording and storing reading from the different sensors. The air relative humidity was computed from the dry-bulb and wetbulb temperatures using the Psychrometric program. For the determination of the optical transmission of the two greenhouse roof, the global solar radiation was measured by two pyranometers (Spectrum Technologies, Inc., ColeParmer, USA) situated in the middle of the two greenhouses. Simultaneously to the measurements of microclimatic conditions, outside variables were also measured and recorded; outside air temperature, relative humidity, wind speed and its direction, and global solar radiation using meteorological station (WatchDog model 550, Cole-Parmer, USA) which installed just above the greenhouses. A mini Thermo-Anemometer (Extech Instruments Corporation, Cole-Parmer, USA) was used to measure the air speed (in the front of the cooling pads) traveling through the greenhouse. Measurements of all previous sensors were centralized on a data logging program (space Ware 6.02 ) with a $30 \mathrm{~s}$ time period, and averaged out on a $5 \mathrm{~min}$. time scale before being processed.

\section{Mathematical modeling}

A microclimatic energy balance can be developed to predict the ambient air temperature inside the greenhouse. It can be simulated by five factors which affect the temperature distribution along the greenhouse; ventilation rate, Evapotranspiration rate, percentage of shading, water evaporation from the cooling pads, and soil evaporation (being neglected) as shown in Fig. (4). The energy balance equation combines theses factors and gives access to the temperature distribution along the greenhouse length.

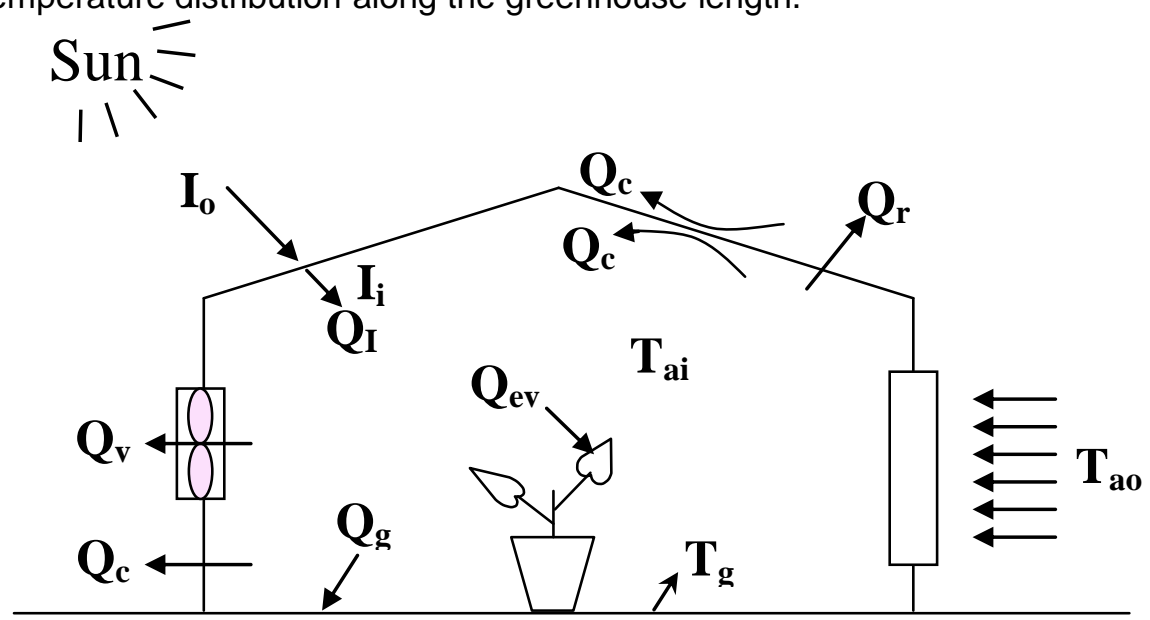

Fig. (4): Schematic diagram of the greenhouse microclimatic energy balance 
The heat energy balance can be expressed as follows (Kittas et al. 2001b ; Sethi and Sharma, 2007)):-

$$
\mathbf{Q}_{1}=\mathbf{Q}_{\mathrm{g}}+\mathbf{Q}_{\mathrm{ev}}+\mathbf{Q}_{\text {loss }}, \quad \text { Watt }
$$

Where, $Q_{l}$, is the solar energy available inside the greenhouse $(W), Q_{g}$, is the heat energy absorbed by the bare area of the floor surface (W), $Q_{\mathrm{ev}}$ is the heat energy consumed in evapotranspiration process $(\mathrm{W})$, and, $\mathrm{Q}_{\text {loss }}$, is the total heat energy losses by conduction, convection, ventilation, and thermal radiation $(\mathrm{W})$.

The solar energy available $\left(Q_{1}\right)$ inside the greenhouse can be computed by the following formula:-

\section{$Q_{1}=\mathbf{I}_{\mathbf{i}} \mathbf{A}_{\mathrm{f}} \quad, \quad$ Watt}

Where, $l_{i}$, is the solar radiation flux incident inside the greenhouse $\left(W / \mathrm{m}^{2}\right)$, and, $\quad A_{f}$, is the floor surface area of the greenhouse $\left(32.0 \mathrm{~m}^{2}\right)$. The solar energy absorbed by the floor can be computed as follows:

$$
\mathbf{Q}_{g}=I_{i} \quad A_{b} \quad \alpha_{g} \quad, \quad \text { Watt }
$$

Where, $A_{b}$, is the bare area of the greenhouse floor $\left(\mathrm{m}^{2}\right)$ and, $\alpha_{g}$, is the absorptivity of the floor (concrete)(0.60, Aldrich and Bartock, 1990). The heat energy consumed by evapotranspiration $\left(Q_{\mathrm{ev}}\right)$ can be calculated as follows:-

$\mathbf{Q}_{\mathrm{ev}}=\mathbf{R} \mathbf{F} \mathbf{Q}_{\mathrm{l}}$, Watt

Where, $\mathrm{R}$, is the rate of evapotranspiration to solar radiation, ranged form 48$52 \%$ (Nelson, 1996), F, is the ratio of floor surface area covered by plants to total floor area $(60 \%)$. The total heat energy losses $\left(Q_{\text {loss }}\right)$ by conduction and convection, ventilation, and thermal radiation can be computed by the following equation:

$$
\mathbf{Q}_{\text {loss }}=q_{c}+q_{v}+q_{r}, \quad \text { Watt }
$$

The heat energy losses by conduction and convection $\left(q_{c}\right)$ can be estimated as follows:-

$$
q_{c}=U_{0} A_{c}\left(T_{a i}-T_{a o}\right), \quad \text { Watt }
$$

Where, $U_{0}$, is the overall heat transfer coefficient $\left(5.7 \mathrm{~W} / \mathrm{m}^{2} .{ }^{\circ} \mathrm{K}, \mathrm{ASAE}, 2004\right)$, $A_{c}$, is the total surface area of the greenhouse cover $\left(88.08 \mathrm{~m}^{2}\right)$, and $T_{a i}$ and $\mathrm{T}_{\mathrm{a} o}$, is the inside and outside air temperature, respectively $\left({ }^{\circ} \mathrm{K}\right)$. The heat energy loss by forced ventilation $\left(q_{v}\right)$ can be computed as follows:

$$
q_{v}=m C p\left(T_{a i}-T_{a o p}\right) \text {, Watt }
$$

Where, $\mathrm{m}$, is the mass flow rate of air exhausted from the greenhouse $(\mathrm{m}=$ $M(\rho) / 3600, \mathrm{~kg} / \mathrm{s}), M$, is the extracting fan discharge $\left(8000 \mathrm{~m}^{3} / \mathrm{hr}\right), \rho$, is the density of air $\left(1.2 \mathrm{~kg} / \mathrm{m}^{3}\right), \mathrm{Cp}$, is the specific heat of air $\left(1007 \mathrm{~J} / \mathrm{kg} .{ }^{\circ} \mathrm{K}\right)$, and $\mathrm{T}_{\text {aop }}$, is the optimal air temperature inside the greenhouse $\left(28^{\circ} \mathrm{C}\right)$. The heat energy loss by thermal radiation $\left(q_{r}\right)$ can be calculated by the following formula:-

$$
q_{r}=\varepsilon_{f} T_{1} \quad \sigma \quad A_{f}\left(T^{4}{ }_{a i}-T^{4}{ }_{s}\right) \text {, Watt }
$$

Where, $\varepsilon_{\mathrm{f}}$, is the mean emittance factor of the inside surface (0.758, Aldrich and Bartock, 1990), $\mathrm{T}_{1}$, is the transmissivity of the greenhouse cover for longwave radiation, $\sigma$, is the stefen-Boltzmann constant $\left(5.67 \times 10^{-8}\right.$ $\left.\mathrm{W} / \mathrm{m}^{2} .{ }^{\circ} \mathrm{K}^{4}\right)$, and, $T_{s}$, is the sky temperature, $\left(T_{s}=0.0552\left(T_{a o}\right)^{1.5}{ }^{\circ} \mathrm{K}\right.$, Ashrae, 


\section{Abdellatif, S. M. et al.}

2005). The energy balance on microclimatic conditions inside the greenhouse during daylight is represented by equation (9). This equation can be rewritten in finite difference form and solved for the greenhouse predicted air temperature $\left(T_{\text {aip }}\right)$ at each hour with respect to the outside air temperature $\left(T_{a o}\right)$ and input and output heat energies at each hour.

$$
\mathrm{T}_{\mathrm{aip}}=\mathrm{T}_{\mathrm{ao}}+\frac{3600}{\mathrm{~m} C \mathrm{Cp}}\left[\mathrm{Q}_{\mathrm{l}}-\mathrm{Q}_{\mathrm{g}}-\mathrm{Q}_{\mathrm{ev}}-\mathrm{q}_{\mathrm{c}}-\mathrm{q}_{\mathrm{r}}\right] \text {, }{ }^{\circ} \mathrm{K}
$$

A computer model has been developed and functioned for computing the energy balance during daylight in sunny summer days, using the previous formulas. The model was implemented as stand-alone program running on IBM compatible microcomputer. The developed mathematical model has been solved with the help of computer program based on MATLAB. The program requires two input files; one contains the simulation parameters and the other contains the input data. The energy balance simplified flowchart for MATLAB program showed in Fig. (5).

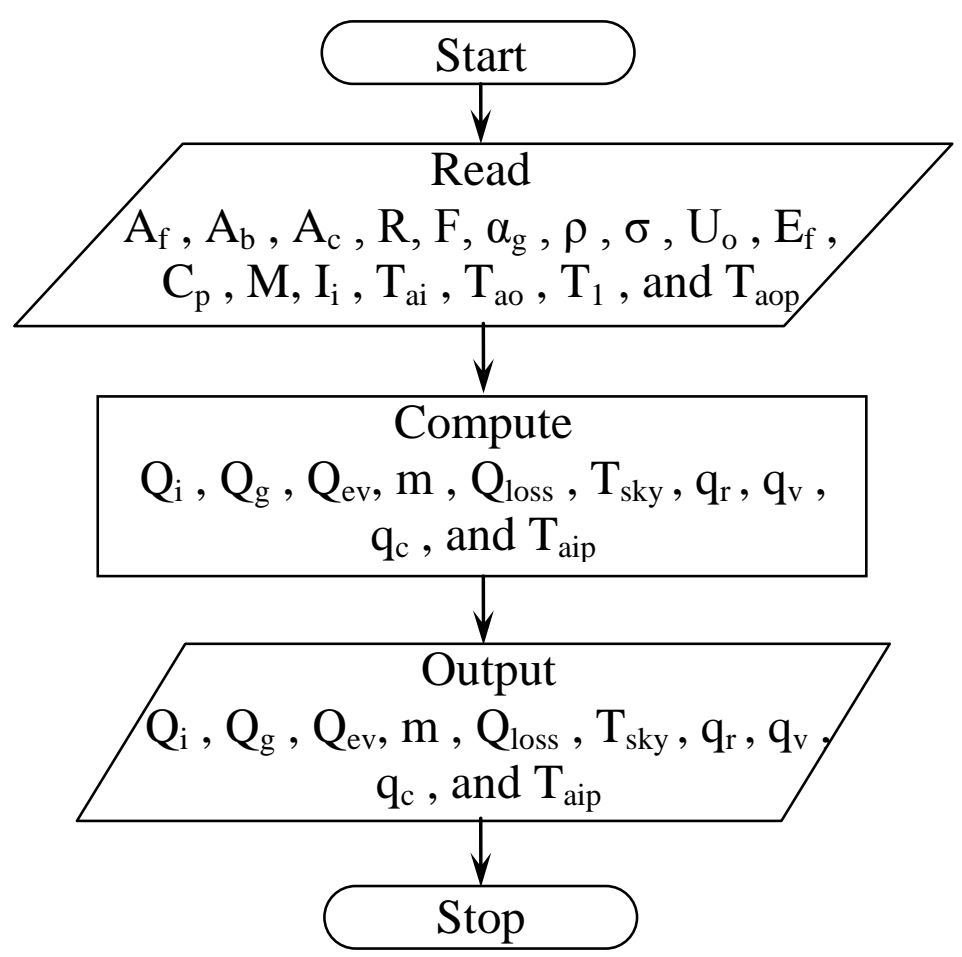

Fig. (5): Energy balance simplified flowchart for MATLAB program.

The evaporative cooling system efficiency can be calculated from the following equation (Ashrae, 2005):- 


$$
\eta_{\mathrm{e}}=\frac{\mathrm{T}_{0}-\mathrm{T}_{\text {pad }}}{\mathrm{T}_{0}-\mathrm{T}_{\mathrm{ow}}} \times 100, \quad \%
$$

Where, $T_{0}$, is the dry-bulb temperature of the outside air just before entering the cooling pads $\left({ }^{\circ} \mathrm{C}\right), \mathrm{T}_{\text {pad }}$, is the dry-bulb temperature of cooled air just leaving the cooling pads $\left({ }^{\circ} \mathrm{C}\right)$ and, $T_{o w}$, is the wet-bulb temperature of the outside air just before entering the cooling pads $\left({ }^{\circ} \mathrm{C}\right)$. The temperature of the air just leaving the cooling pads $\left(T_{\text {pad }}\right)$ can be calculated as a function of cooling efficiency and the outside climatic conditions, from the following equation (ASHRAE, 2005):

$$
\mathrm{T}_{\text {pad }}=\mathrm{T}_{\mathrm{o}}-\eta_{\mathrm{e}}\left(\mathrm{T}_{\mathrm{o}}-\mathrm{T}_{\text {ow }}\right),{ }^{\circ} \mathrm{C}
$$

The saturation vapour pressure of the air $\left(\mathrm{VP}_{\text {sat }}\right)$ in psi can be calculated as follows (Prenger and Ling, 2004):-

$$
\mathrm{Z}=\frac{\mathrm{A}}{\mathrm{T}}+\mathrm{B}+\mathrm{CT}+\mathrm{DT}^{2}+\mathrm{ET}^{3}+\mathrm{F} \ln (\mathrm{T}), \mathrm{psi}
$$

Where:

$$
\begin{array}{rlrl}
\mathrm{A} & =-1.044039 \times 10^{4}, & \mathrm{~B}=-11.294650 \\
\mathrm{C}=-2.7022355 \times 10^{-2}, & \mathrm{D}=1.289036 \times 10^{-5} \\
\mathrm{E}=-24780681 \times 10^{-9}, & \mathrm{~F}=6.5459673 \\
\mathrm{~T} & =\text { Temperature of the air in }{ }^{\circ} \mathrm{R}\left({ }^{\circ} \mathrm{R}={ }^{\circ} \mathrm{F}+459.67\right) .
\end{array}
$$

The vapour pressure of the air (VPair) in psi at the actual air relative humidity $(\%)$ of the greenhouse air $(\mathrm{RH})$ can be determined from the following formula:

$$
\mathrm{VP}_{\text {air }}=\left(\mathrm{VP}_{\text {sat }} \times \mathrm{RH}\right) / \mathbf{1 0 0}, \quad \text { psi }
$$

The vapour pressure deficit (VPD) can be computed as follows:

$$
\mathrm{VPD}=\mathrm{VP}_{\text {sat }}-\mathrm{VP}_{\text {air }} \text {, psi }
$$

The values of vapour pressure deficit (VPD) can be calculated in $\mathrm{kPa}$ by multiplying the values in psi by $6.894(1 \mathrm{psi}=6.894 \mathrm{kPa})$. The previous formulas were used to calculate the vapour pressure deficit (VPD) using computer Excel-sheet software.

It should be mentioned that, the greenhouses equipped with misting cooling system and fan-pad system are referred to as greenhouse 1 (G1) and greenhouse 2 (G2), respectively.

\section{RESULTS AND DISCUSSION}

The objective of present study was to evaluate the effects of misting and fan-pad evaporative cooling systems on the microclimate and vapour pressure deficit in fiberglass gable-even-span greenhouses. The optimization of air temperature, relative humidity, and vapour pressure deficit in greenhouses are of particular importance in relation to plant growth, development, and productivity. In order to achieve optimum indoor conditions, it is necessary to ventilate and cool the greenhouse, particularly during the hot seasons. The primary objective of a greenhouse is to produce higher yield outside the cultivation season, which is possible by maintaining the optimum microclimate at every stage of the crop growth. An appropriate cooling system can be coupled with the greenhouse for this purpose. This, as 
a result, has significant impact on the cultivation time, quality and quantity of the products.

Effect of outside climatic conditions on inside microclimate of the two greenhouses

Protected cultivation of vegetable crops in Egypt during summer season are favored owing to high humidity, tremendous intensity of solar radiation, and air temperature fluctuation, and high vapour pressure deficit during that period. The obtained results presented in the following sections concerned hourly average measurements recorded during the experimental period (April, May, June, and July). The measurement data were averaged on 30 minutes and covered the period $6.00-18.00 \mathrm{~h}$ standard time. Solar noon corresponded approximately to $12.30 \mathrm{~h}$ solar time.

\section{1-Solar radiation flux incident inside and outside the greenhouses}

The hourly average solar radiation flux incident outside the greenhouses was 500.1, 592.9, 649.5, and $618.5 \mathrm{~W} / \mathrm{m}^{2}$ for April, May, June, and July, respectively. While, this amount recorded inside the greenhouse during the same time was $267.7,326.2,372.6$, and $345.6 \mathrm{~W} / \mathrm{m}^{2}$, respectively. Consequently, the hourly average effective transmittance of the corrugated fiberglass cover and shading black net screen was 53.53\%, 55.02\%, 57.37\%, and $55.88 \%$, respectively. These obvious differences in effective transmittance of the corrugated fiberglass cover, and shading black net can be attributed to the solar incident angles which were varied from month to another during this experimental work.

To determine the solar energy flux incident inside the greenhouses as a function of solar energy outside, the solar radiation flux incident on the horizontal level inside the greenhouse $\left(R_{i}\right)$ during the experimental period was plotted against solar radiation flux incident outside $\left(R_{0}\right)$ as revealed in Fig. (6). Regression analysis revealed a highly significant linear relationship. $(r=0.922 ; P \leq 0.001)$ between these parameters. The regression equation for the best fit was:

$$
\mathbf{R i}=0.5607\left(R_{0}\right)
$$

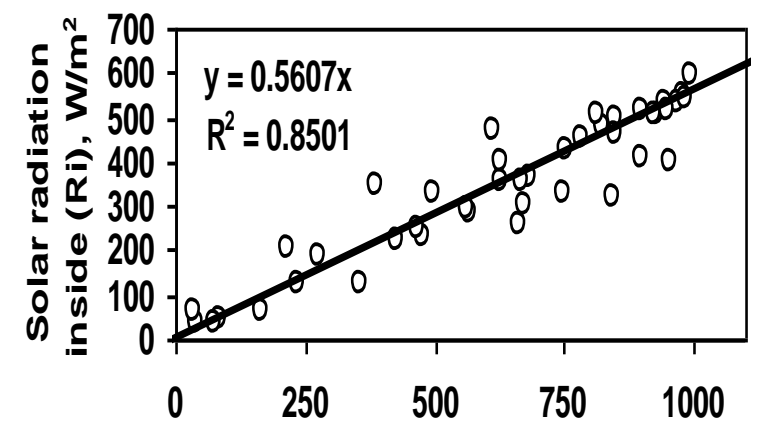

Solar radiation outside $(\mathrm{Ro}), \mathrm{W} / \mathrm{m}^{2}$

Fig. (6): Solar radiation incident inside the greenhouse versus that incident outside. 


\section{Ambient air temperatures inside and outside the greenhouses}

Air temperatures in Egyptian greenhouses either covered with polyethylene or fiberglass reinforced plastic can easily exceed $50{ }^{\circ} \mathrm{C}$ during the summer if they are not equipped with evaporative cooling system. These conditions are the main responsible for the decrease in fresh yield and quality of greenhouse production.

The change in air temperature inside the two greenhouses (G1 and G2) equipped by misting and fan-pad evaporative cooling systems, respectively, were compared with the outside air temperatures as an important measure of the effectiveness of the two different cooling systems. The air temperatures inside the two greenhouses increased gradually with the day time according to the intensity of solar radiation flux incident. This is in agreement with the data published by Aldrich and Bartok (1990), Abak et al. (1994), and Nelson (1996), when they reported that, in greenhouse without cooling system, the air temperature inside the greenhouse changed according to the solar radiation reaching the greenhouse during the daylight.

The hourly average air temperatures inside the two greenhouses (G1, and G2) between 8.00 and $18.00 \mathrm{~h}$, respectively, were $31.3^{\circ} \mathrm{C}$ and $26.9^{\circ} \mathrm{C}$. While, the hourly average air temperature outside the greenhouses was $29.2^{\circ} \mathrm{C}$. The air temperature inside the greenhouse 1 (equipped with misting evaporative cooling system) varied between $24.0^{\circ} \mathrm{C}$ and $35.2^{\circ} \mathrm{C}$, whereas the outside air temperature ranged from $19.1^{\circ} \mathrm{C}$ to $34.0^{\circ} \mathrm{C}$. The differences in ambient air temperatures inside and outside during daylight varied from hour to hour, month to another, and during the experimental period, due to change in the intensity of solar energy available inside the greenhouses. These differences reflect the variations in the heat energy balance resulting from the shortwave radiation transmitted into the greenhouses and long-wave radiation transferred out. The greater differences between air temperatures inside and outside the greenhouses (G1, and G2) occurred at and around noon (from 11 to 13 hour) due to the great level of thermal trapping recognized at that time and heat energy accumulation. These differences during April, May, June, and July for greenhouse (G1) were $4.3,2.5,1.6$, and $1.2^{\circ} \mathrm{C}$, respectively. Meanwhile, these differences for greenhouse (G2) at the same time and period were $0.3,-1.9,-4.1$, and $3.8^{\circ} \mathrm{C}$, respectively.

The air temperatures at the level of cucumber crop were uniform inside the two greenhouses, due to the air inside the greenhouses was continuously moved by the extracting fans. This is in agreement with the data published by Nelson (1996), and Kittas et al. (2003) when they reported that, as the air inside the greenhouse is continuously moving, ambient air temperatures are uniform, humidity surroundings leaf surface is reduced, and carbon dioxide levels are thus decreased. The temperature of the cucumber crop leaves during the majority of daylight time was lower than the ambient air temperature inside the greenhouse equipped with fan-pad evaporative cooling system which prevented occurrence of plant thermal stress and consequently reduced the risk of plant water stress and avoid injury and death from wilting. Whereas, the air temperature in the greenhouse 1 (equipped with misting system) around noon was higher than that outside by 
$2.4^{\circ} \mathrm{C}$, because misting system was relatively poor. It is imperative to predict the hourly average ambient air temperature inside the two greenhouses during daylight according to the ambient air temperature outside the greenhouses under specific conditions. The air temperatures recorded inside the two greenhouses $\left(T_{\text {ai }}\right)$ during the experimental period were used as a function of ambient air temperature outside the greenhouses $\left(T_{a 0}\right)$ as revealed in Fig. (7). Regression analyses showed a highly significant linear relationship $(r(G 1)=0.935 ; r(G 2)=0.815 ; P \leq 0.001)$ between these parameters. The best fit equations relating the ambient air temperature inside the two greenhouses (under specific circumstances) to that outside were :-

$$
\begin{array}{ll}
\mathrm{T}_{\mathrm{ai}}(\mathrm{G} 1)=12.221 & +0.6607\left(\mathrm{~T}_{\mathrm{ao}}\right) \\
\mathrm{T}_{\mathrm{ai}}(\mathrm{G} 2)=16.249 & +0.3671\left(\mathrm{~T}_{\mathrm{ao}}\right)
\end{array}
$$
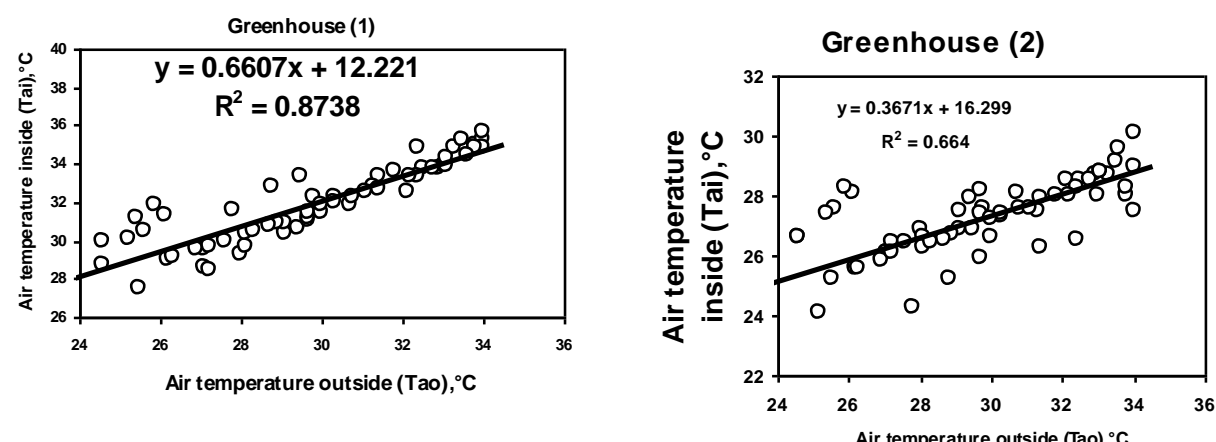

Fig. (7): The relationship between inside and outside air temperatures for the two greenhouses during the experimental period.

This figure also showed that the air temperature inside the fan-pad greenhouse was uniformity distributed more than that inside the misting greenhouse. The hourly average maximum air temperature inside the greenhouse, (G1) were $28.7,30.7,33.0$, and $31.9^{\circ} \mathrm{C}$ for April, May, June, and July, respectively. Meanwhile, for greenhouse (G2) they were 25.7, 26.3, 27.3 and $27.9^{\circ} \mathrm{C}$, at the same period, respectively. The hourly average air temperatures in greenhouse 1 (G1) around noon (between 11.00 and 14.00 h), respectively, were $31.2,32.5,34.4$, and $33.4{ }^{\circ} \mathrm{C}$ for April, May, June, and July. Whereas, the air temperatures recorded inside the greenhouse 2 (G2) at the same period were $26.8,27.8,28.3$, and $28.6^{\circ} \mathrm{C}$, respectively. The differences between the maximum air temperatures and the set point air temperature $\left(28^{\circ} \mathrm{C}\right)$ inside the greenhouse $(\mathrm{G} 1)$ were $3.2,4.5,6.4$, and $5.4^{\circ} \mathrm{C}$, respectively. While for greenhouse $(\mathrm{G} 2)$ they were $-1.2,-0.2,0.3$, and $0.6^{\circ} \mathrm{C}$, respectively. The scattering data of the ambient air outside the greenhouse represented a sinusoidal function with small amplitude of a function. Greater amplitude was observed inside the greenhouse, because of the material cover (translucent materials) trapping the long wave thermal radiation which reflected and emitted from the plants, greenhouse frame, and walks. This thermal trapping may increase the heat stress on cucumber crop, which often reduce the photosynthesis process. 
The experimental data also showed that, the evaporative cooling system using fan-pad system (in greenhouse 2) able to keep the greenhouse air temperature below the set point temperature in all circumstances. Moreover, the internal air temperature stayed $8^{\circ} \mathrm{C}$ below outside, even during hot afternoons (air temperatures up to $36^{\circ} \mathrm{C}$ ), owing to the low outside air relative humidity levels and high efficiency of the evaporative cooling system (near $80 \%$ ). Whereas, the evaporative cooling used misting system (greenhouse 1) kept the greenhouse air temperature above the set point temperature by an average of $4.9^{\circ} \mathrm{C}$. Therefore, the internal air temperature only stayed $4.0^{\circ} \mathrm{C}$ below outside air temperature.

\section{Air relative humidity inside and outside the greenhouses}

The air temperature inside the two greenhouses which continuously ventilated with air drawn from an evaporative cooling and misting system ranged from $22{ }^{\circ} \mathrm{C}$ to $36{ }^{\circ} \mathrm{C}$ on bright days, and the air relative humidity reached $85 \%$ at night but fluctuated during the daylight. The air relative humidity outside and inside the two greenhouses decrease gradually with solar time from sunrise until they reached the minimum values at or around noon, due to increase in solar energy flux incident either outside or inside the greenhouses at that period. They then increase gradually till they approach the maximum values just before the sunrise time. The air relative humidity outside and inside the greenhouses revealed the same trend. They varied from hour to hour, day to another, and during the month according to the intensity of solar radiation and wind plowing over the place.

The hourly average air relative humidity outside the greenhouses for April, May, June, and July was $33.2 \%, 25.9 \%, 29.7 \%$, and $34.8 \%$, respectively. While, these values inside the greenhouse (G1) for the same period, respectively, were $58.1 \%, 70.9 \%, 67.5 \%$, and $68.9 \%$,. Meanwhile, the air relative humidity inside the greenhouse (G2) for the same period was $53.7 \%, 48.9 \%, 49.6 \%$, and $59.6 \%$, respectively. The air relative humidity inside the two greenhouses (G1) and (G2) at daylight (from 8 to 18 hour) were greater than those outside the greenhouses on an average by $35.5 \%$ and $22.1 \%$, respectively. The hourly average air relative humidity inside the two greenhouses during daylight (from 8 to 18 hour) was $66.4 \%$ and $53 \%$, respectively. Therefore, the air relative humidity inside the greenhouses are considered to be suitable for growing and producing cucumbers crop, because the normal vegetative growth and productivity of protected cropping are generally occurred at air relative humidity between $50-80 \%$, and air temperature between $20-35^{\circ} \mathrm{C}$ (Nelson, 1996 ; Öztürk and Başçetinçelik, 2003 ; Argus, 2009). Low air relative humidity inside the greenhouses (HR< $25 \%$ ) increases the evaporation demand on the plant leaves to the extent that heat and water stresses can occur. During the daylight time, the air relative humidity inside the greenhouse (G2) was lower than that inside the greenhouse (G1) by $13.4 \%$. This difference can be attributed to air exchange rate, vapour pressure gradient between the leaf and air, water or humidity added to the air from misting cooling system, air temperature inside, and leaf temperature of the plant.

The water loss from the plant and add to the inside air is often determined by; the difference in water vapour concentration between inside 
the leaf and outside, and by the resistance to movement of water molecules from inside the leaf to outside. The resistance varies according to the length of the path which water molecules must traverse, and the size of the stomata opening (Nelson, 1996). As the leaf temperature is reduced due to the evaporative cooling, the internal vapour pressure of the leaf is lowered and thus the water loss from the plant is less, and vice versa. Air relative humidity is the ratio between actual vapour pressure and the vapour pressure of water in air if the air is saturated at the same temperature. The saturation pressure and air relative humidity are changed according to change the air temperature inside the greenhouse. With evaporative cooling system, lowering of the dry bulb temperature will generally raise the air relative humidity (Hanan, 1970). Furthermore, water is always being added to the ambient air inside the greenhouse from transpiring plants and evaporating water from cooling system.

The solar energy available inside the greenhouse is often utilized to evaporate free water from the leaf, rather than raising leaf temperature and increasing water loss from the plant into inside air. When a non-saturated air comes in contact with free moisture and the two are thermally isolated from outside heat source, there is a transfer of mass and heat. Because of the vapour pressure of the free water surface is higher than that of the unsaturated air, water transfers in response to the differential. The transfer involves a change of state from liquid to vapour, requiring heat of vaporization.

\section{Vapour pressure deficit (VPD)}

The vapour pressure is a good indicator of plant stress brought about by either excessive transpiration (high VPD values) or the inability to transpire adequately (low VPD values). Vapour pressure deficit relates to the customary thinking about air relative humidity. Higher vapour pressure deficit means that, the air surrounding the plant has a higher capacity to hold water, stimulating water vapour transfer (transpiration) into the air in this low air relative humidity conditions. Lower vapour pressure deficit, on other hand, means the air surrounding the plant is at or near saturation, so the air cannot accept moisture from the leaf in this high air relative humidity condition.

The vapour pressure deficit of the air surrounding the cucumber plants increased gradually with solar time (between 8.00 and 12.00 noon) until they reached the maximum values $(2.29$ and $2.09 \mathrm{kPa})$, as the intensity of solar radiation and air temperature were increased, and the air relative humidity was decreased. They then decreased till approached the minimum values just before the sunrise time. The vapour pressure deficit inside the two greenhouses (G1 and G2) showed the same trend during the experimental period. They varied from hour to hour, day to another, and during the experimental period, owing to the intensity of solar radiation, air temperature, and air relative humidity. The hourly averages vapour pressure deficit inside the greenhouse 1 (equipped with misting system) were 1.65, 1.29, 1.64, and $1.47 \mathrm{kPa}$, for April, May, June, and July, respectively. Whereas, these values inside the greenhouse 2 (equipped with fan-pad system) for the same period, respectively, were $1.53,1.75,1.83$, and $1.53 \mathrm{kPa}$. When the air vapour pressure deficit is too high (VPD $>3 \mathrm{kPa}$ ) at air relative humidity too low $(\mathrm{RH}$ 
$<35 \%)$ and air temperature very high $\left(\mathrm{Ta}>35^{\circ} \mathrm{C}\right)$, the rate of evaporation from the leaves can exceed the supply of water into the roots. This in turn will cause the stomata to close, and photosynthesis to slow or stop. Once the stomata close, the leaves are at risk of high temperature injury since evaporative cooling is reduced due to the lack of water to evaporate. To avoid injury and death from wilting, many plant species will either curl their leaves or orient them downward in an attempt to expose less surface area to the sun's rays. This condition can significantly downgrade the quality of potted and foliage plants and can also reduce the growth rate and quality of vegetable crops.

Several studies (Bailey, 1995 ; Elad et al.,1996 ; Pringer and Ling, 2004; Argus, 2009) that explored disease pathogen survival at different climate levels revealed two critical values of air vapour pressure deficit. The studies showed that fungal pathogens survive best below $0.43 \mathrm{kPa}$ vapour pressure deficit. Furthermore, disease infection is most damaging below 0.20 $\mathrm{kPa}$, which may occur at night time with too high air relative humidity $(>85 \%)$ and very low air temperature $\left(<15^{\circ} \mathrm{C}\right)$. The vapour pressure deficit during daylight must not exceed $2.0 \mathrm{kPa}$, to avoid heat and water stresses.

The obtained data of air vapour pressure deficit inside the two greenhouses revealed that, the VPD at and around noon was higher than the optimum level (VPD $<1.30 \mathrm{kPa}$ ). Thus, the greenhouses climatic conditions should be kept underneath $1.30 \mathrm{kPa}$ to avoid injury and death from wilting. They also showed that, under evaporative cooling using misting system (G1), the air relative humidity appeared to be at the optimal level $(61.7-67.6 \%)$ particularly at the critical period of daylight (from $10.00-14.00 \mathrm{~h}$, solar time), but the air temperature at that time $\left(30.5-33.1^{\circ} \mathrm{C}\right)$ was higher than that of the optimum level $\left(28^{\circ} \mathrm{C}\right)$. Whereas, under evaporative cooling using fan-pad system (G2), the air relative humidity at the critical period $(48.6-51.8 \%)$ was lower than the optimal level (65\%), but the air temperature surrounding the plants $\left(27.2-28.0^{\circ} \mathrm{C}\right)$ was at and around the desired level for cucumber crop. Therefore, the air relative humidity must be raised to $65 \%$ at that period by increasing the water flow rate through the cooling pads.

To determine the most important parameters affecting air vapour pressure deficit (VPD) inside the two greenhouses (G1 and G2), the air temperatures (Tai) and air relative humidity $(\mathrm{RH})$ were functioned to examine their relationships with the vapour pressure deficit. Multiple regression analysis revealed a highly significant linear relationship $(r=0.9958 ; P \leq$ 0.001 ) between these parameters. It also showed a highly significant linear relationship between the vapour pressure deficit and the air relative humidity ( $P \leq 0.001$ ), but the relationship between the vapour pressure deficit and the air temperature was significant at level of 0.01 . The multiple regression equations for the best fit were:

$\operatorname{VPD}(\mathrm{G} 1)=1.8125-0.0455(\mathrm{RH})+0.0882\left(\right.$ Tai) $R^{2}=0.9900$
$\operatorname{VPD}(\mathrm{G} 2)=1.3184-0.0358(\mathrm{RH})+0.0840($ Tai $) \quad R^{2}=0.9933$ 
Effectiveness of evaporative cooling using misting and fan-pad systems

Cooling capacity is dependent upon the volume of air flow and the saturation efficiency. Saturation efficiency, and the effectiveness of evaporative cooling either using fan-pad or misting system are strongly dependent upon such factors as; length of cooling operation period, air velocity through the pad and greenhouse and water flow rate through the cooling media. The effectiveness of the two evaporative cooling systems during the experimental period are summarized and listed in Table (2). It shows that the daily average effectiveness of the evaporative cooling systems inside the two greenhouses (G1 and G2) during spring and summer seasons was $54.1 \%$ and $76.6 \%$, respectively. Consequently, the cooling system using fan-pad system inside the greenhouse (G2) was on the average more efficient than the misting system inside the greenhouse (G1) by $22.5 \%$ due to the cooling operation period for the greenhouse (2) was longer than that for the greenhouse (1), accordingly, the water temperature of cooling system (2) was lower than that in misting system (G1). The effectiveness of cooling pad was varied from time to time, day to another and during the experimental period according to the air relative humidity and ambient air temperature outside the greenhouses. As the exterior air relative humidity is decreased lower than $30 \%$, more cooling effect is achieved making the cooling system more efficient. Substantial temperature decreases were obtained when the air relative humidity of outside air was less than $30 \%$ and outside air temperature exceeded $32.8^{\circ} \mathrm{C}$. For these circumstances the two cooling systems provided a cooling effect ranged between 1.3 to $3.0^{\circ} \mathrm{C}$ at air relative humidity $(\mathrm{RH})$ ranged from $30.5 \%$ to $60.2 \%$, respectively.

Table (1): Daily average exterior climatic conditions including, air relative humidity $(\mathrm{RH})$, dry-bulb air temperature $\left(T_{0}\right)$, wetbulb air temperature $\left(T_{o w}\right)$, and wet-bulb depression $\left(T_{w d}\right)$; and interior just leaving the cooling pads $\left(T_{\text {pad }}\right)$, and underneath the nozzles of misting system $\left(T_{\text {idb }}\right)$, cooling effect $\left(T_{d d}\right)$ and effectiveness of cooling system $\left(\eta_{\text {eff }}\right)$ for the two greenhouses.

\begin{tabular}{|c|c|c|c|c|c|c|c|c|c|c|}
\hline \multirow{3}{*}{ Month } & \multirow{2}{*}{\multicolumn{4}{|c|}{ Exterior climatic conditions }} & \multicolumn{6}{|c|}{ Evaporative cooling system } \\
\hline & & & & & \multicolumn{6}{|c|}{ Misting system (G1) Fan-pad system (G2) } \\
\hline & \multicolumn{4}{|c|}{$\overline{\mathrm{RH}}, \% / \mathrm{T}_{\text {odb }}{ }^{\circ} \mathrm{C} / \mathrm{T}_{\text {owb }}{ }^{\circ} \mathrm{C} / \mathrm{T}_{\text {wd }},{ }^{\circ} \mathrm{C}$} & $T_{\text {it }}{ }^{\circ} \mathrm{C} \mathrm{C}$ & $\mathrm{T}_{\text {dd }},{ }^{\circ}$ & 2 & $T_{\text {pad, }}{ }^{\circ}$ & $\mathrm{T}_{\mathrm{dd} d}{ }^{\circ} \mathrm{C}$ & $\eta_{\text {eff }}, \%$ \\
\hline April & & & & & 20.1 & 5.3 & 0 & 17.9 & 7.5 & 75.0 \\
\hline lay & & & & & & & & 18 & 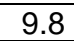 & 79.7 \\
\hline & & & & & & & & & & 77.4 \\
\hline dly & & & & & 25 & & 5 & 23 & 8.5 & 74.6 \\
\hline lean & 30.9 & 29.2 & 17.7 & 11.5 & 23.0 & 6.2 & 54.1 & 20.4 & 8.9 & 76.6 \\
\hline
\end{tabular}

Effectiveness of cooling system $\left(\eta_{\text {eff }}\right)$ for the two greenhouses was plotted against air relative humidity $(\mathrm{RH})$ outside the greenhouses (Fig. 8). Regression analysis revealed a highly significant linear relationship $(r(\mathrm{G} 1)=$ $0.9993, r(G 2)=0.9987 ; P \leq 0.001$ ). Regression analysis also showed that more difference between the two cooling systems occurred at the beginning and end of cooling process during this experimental work, due to the high air 
relative humidity outside the greenhouse and water temperature in the cooling system. Therefore, the effectiveness of cooling system in greenhouse (G2) was greater than that in greenhouse (G1) by $22.5 \%$. The regression equations for the best fit were:

$\eta_{\text {eff }}($ cooling system in G1) $=67.432-0.4311(\mathrm{RH})$

$\eta_{\text {eff }}($ cooling system in G2) $=94.889-0.5911(R H)$

The degree of cooling obtained from the evaporative cooling systems was directly related to the wet-bulb depression (difference between the dry and wet-bulb temperatures of outside air) that occurred with a given set of climatic conditions. The wet-bulb temperature decreased as energy was absorbed during converting water from the liquid phase to the vapour phase.

As shown in equation (1) mathematical model of heat energy balance indicates that, the solar energy available inside the greenhouse was almost equaled to the sum of absorbed solar energy by the bare area of floor surface, heat energy consumed in evapotranspiration process, and heat energy losses. The combining of the four varies heat energy terms; the input heat energy (solar energy available), the heat energy stored (absorbed solar energy by the bare area of floor surface), the heat energy consumed in evapotranspiration process, and the total heat energy loss from the greenhouses produced the accumulated heat energy in various substances according to the heat energy balance equation which can be obtained by performing the following model:-

$Q_{\mathrm{acc}}=\mathbf{Q}_{\mathrm{l}}-\mathbf{Q}_{\mathrm{g}}-\mathbf{Q}_{\mathrm{ev}}-\mathbf{Q}_{\text {loss }}$
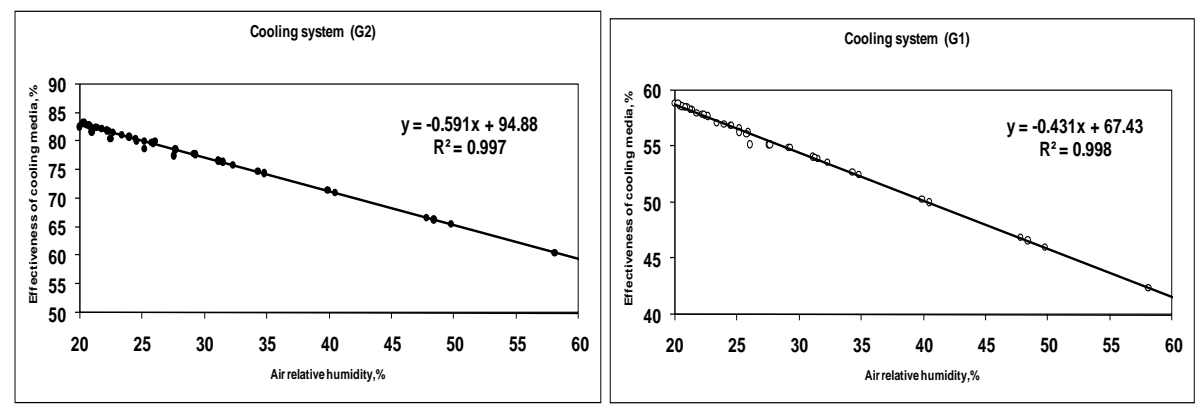

Fig. (8): Effectiveness of cooling system versus exterior air relative humidity for greenhouses (G1) and greenhouses (G2)

The computed data of the model indicate that, the difference between input heat energy and output heat energy yielded the accumulated heat energy. It also revealed that, the ratio of output heat energy to the input heat energy presented the validation of heat energy balance model. The validation of the mathematical model which described the relationship between the input and output heat energies for the two greenhouses G1 and G2 was $96.57 \%$ and $95.99 \%$, consequently, about $3.43 \%$ and $4.01 \%$ of the total input heat energy was accumulated, respectively.

The predicted air temperature $\left(T_{\text {aic }}\right)$, of the model was plotted against the measured air temperature $\left(T_{\text {aim }}\right)$ inside the two greenhouses as shown in 
Fig. (9). Regression analysis revealed a highly significant linear relationship ( $r$ $(G 1)=0.998$ and $r(G 2)=0.999 ; P \leq 0.001$ ) between these parameters for greenhouse G1 and greenhouse G2, respectively. The regression equations for the best fit were:-

$$
\begin{aligned}
& \mathrm{T}_{\text {aic }}(\mathrm{G} 1)=1.0511\left(\mathrm{~T}_{\text {aim }}\right) \\
& \mathrm{T}_{\text {aic }}(\mathrm{G} 2)=1.0393\left(\mathrm{~T}_{\text {aim }}\right)
\end{aligned}
$$

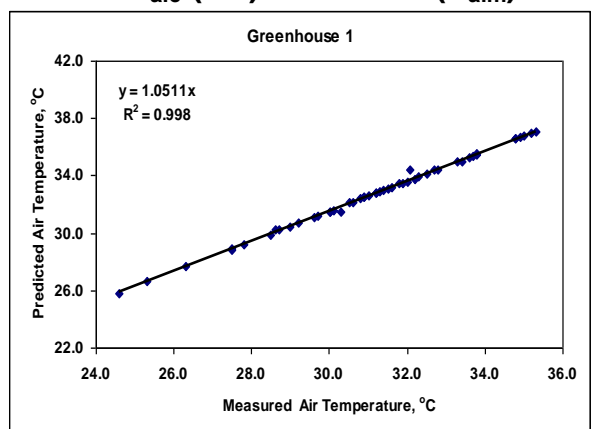

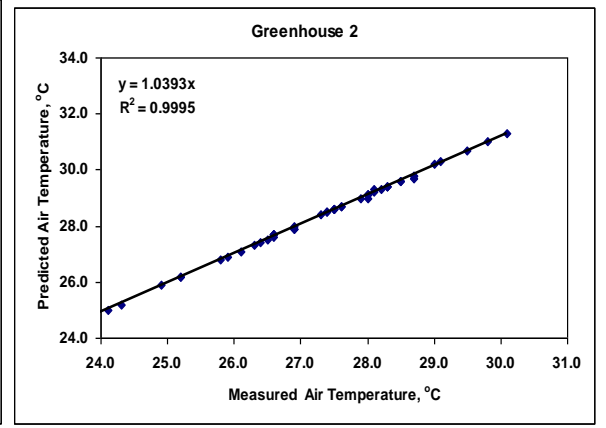

Fig. (9): Correlation of predicted and measured air temperatures inside the two greenhouses (G1 and G2) during the experimental period.

\section{Effect of the two Evaporative Cooling Systems on Growth and Productivity of Cucumber Crop}

Protected vegetable production in greenhouses can afford several advantages to producers. They include the ability to moderate temperature during various seasons of the year, wind protection and insect protection. In the past ten years, greenhouse production of vegetables in different countries such as Egypt has been soared. Cucumbers were planted on April 2 of 2009, and growth began ten days later on April 12, and continued until early August of 2009 (16 weeks). The weekly average leaves number of cucumber plants inside the two greenhouses (G1 and G2) during the experimental period was 1.9 and 2.2 leaf/week, respectively. The number of leaves inside the greenhouse (G2) was on the average $15.79 \%$ more than that in the greenhouse (G1), due to the effectiveness of the two different cooling systems, and consequently the microclimatic conditions. The weekly averages stem length of cucumber plants inside the two greenhouses (G1 and G2) were 14.2 and $17.5 \mathrm{~cm} /$ week, respectively. Consequently, greenhouse (G2) increased the growth rate of plants on the average by $23.24 \%$ as compared with the greenhouse (G1). Variations in stem length occurred, due to the difference in cooling systems, and the location of the row inside the greenhouse during the growth stages. The greatest stem length was achieved from the median row in each greenhouse, due to the same reasons discussed previously. This variation may be attributed to the reaction rates of various metabolic processes, absorption rate of nutrient elements, and release of water by root system, which strongly affected by the microclimatic conditions, particularly the air temperature and air relative humidity. As the number of leaves is increased, the green surface area of leaves is increased, and the biochemical processes are thus increased 
making the photosynthesis process more efficient (Nelson, 1996). The rate of vegetative growth was high and maintained the same throughout the growing season for the two greenhouses.

Cucumbers growth was started on April 12 of 2009, and harvest began one month later on May 12, and continued until early August of 2009. Some cultivars of cucumber produced over 30 fruit on 12 harvests from May 12 till August 2, 2009. Most of these fruits were in the fancy grade and a small percentage of them were cull fruits. Due to the reasons discussed previously, the number of fruits seated on the plants for the two greenhouses were 16.74 and 24.16 fruit/plant, respectively. Consequently, greenhouse (G2) increased the rate of fruit set on the average by $44.32 \%$ as compared with greenhouse (G1). Owing to all previous reasons, the total fresh yield of cucumber crop per square meter for greenhouse (G1) and greenhouse (G2) was 3.805 and $5.491 \mathrm{~kg} / \mathrm{m}^{2}$, respectively. Therefore, the greenhouse (G2) was found to be on the average $1.686 \mathrm{~kg} / \mathrm{m}^{2}(44.31 \%)$ more productive than the greenhouse (G1). A statistical analysis indicated that, there was a significant difference $(5 \%)$ between the two greenhouses in production of cucumber crop.

\section{Conclusion}

The main goal of the present study was to study and determine the most important factors affecting protected cropping under hot and humid climatic conditions. The objective of this research work also was to compare between two different evaporative cooling systems (misting system and fan pad system) under the same glazing material (fiberglass reinforced plastic (FRP). Based on the experimental results conducted, the following main conclusions may be drawn from the present study:-

(1) The hourly averages solar radiation recorded outside and inside the greenhouse during the experimental period were 590.3 and $331.0 \mathrm{~W} / \mathrm{m}^{2}$, respectively. Consequently, the effective transmittance of the fiberglass cover with shading black net screen was $56.07 \%$.

(2) The greater differences between air temperatures inside and outside the two greenhouses occurred at and around noon (from 11 to $13 \mathrm{~h}$ ) due to high thermal trapping at that period. These differences during April, May, June, and July for greenhouse (G1) were $4.3,2.5,1.6$, and $1.2^{\circ} \mathrm{C}$, respectively. Meanwhile, these differences for greenhouse (G2) at the same time and period were $0.3,-1.9,-4.1$, and $-3.8^{\circ} \mathrm{C}$, respectively.

(3) The hourly average air relative humidity inside the two greenhouses during daylight (from 8 to 18 hour) was $66.4 \%$ and 53\%, respectively. Consequently, the evaporative cooling using misting system increased the air relative humidity by $13.4 \%$ above the evaporative cooling using fan-pad system, due to more water supplied from the misting system.

(4) The hourly averages vapour pressure deficit inside the greenhouse 1 (equipped with misting system) were 1.65, 1.29, 1.64, and $1.47 \mathrm{kPa}$, for April, May, June, and July, respectively. Whereas, these values inside the greenhouse 2 (equipped with fan-pad system) for the same period, respectively, were $1.53,1.75,1.83$, and $1.53 \mathrm{kPa}$.

(5) The greatest values of cooling effect for $\mathrm{G} 1$ and $\mathrm{G} 2\left(0.7^{\circ} \mathrm{C}\right.$ and $5.8{ }^{\circ} \mathrm{C}$, respectively) and cooling efficiencies (54.1\% and $74.9 \%$, respectively) 


\section{Abdellatif, S. M. et al.}

were achieved with the greatest value of wet-bulb depression $\left(8^{\circ} \mathrm{C}\right)$ and lowest value of air relative humidity (19.5\%).

(6) The validation of the mathematical model which described the relationship between the input and output heat energies for the two greenhouses G1 and G2 was $96.57 \%$ and $95.99 \%$, consequently, about $3.43 \%$ and $4.01 \%$ of the total input heat energy was accumulated inside the greenhouses, respectively.

(7) The total fresh yield of cucumber crop per square meter for greenhouse (G1) and greenhouse (G2) was 3.805 and $5.491 \mathrm{~kg} / \mathrm{m}^{2}$, respectively. Therefore, the greenhouse (G2) was produced $1.686 \mathrm{~kg} / \mathrm{m}^{2}(44.31 \%)$ more than the greenhouse (G1).

\section{Acknowledgments}

The author gratefully acknowledges the Egyptian Academy of Scientific research and Technology (ASRT) Ministry of higher education and scientific research for providing all the facilities used in this research work. Warm thanks are due to the staff of the Horticulture and Soil Departments, Faculty of Agriculture, University of Mansoura.

\section{REFERENCES}

Abak, K. ; Baytorun N. ; and Altuntas O. (1994) "Influence of mulching and plastic water tubes on the development and productivity of organically grown greenhouse tomato" Acta Horti. 366: 169-173.

Aldrich, R. A. ; and Bartok, J. W. (1990) "Greenhouse Engineering" ed. Ithaca, New York, 14853

Arbel, A. Yekutieti, O. ; and Barak, M. (1999) "Performance of a fog system for cooling greenhouse" J. Agric. Eng. Res. 72: 129-136

Argus Control System LTD (2009) "Understanding and using VPD" www.agruscontrols.com, Canada V4B 3 Y9

ASAE Standards (2003), American Society of Agricultural Engineers "Heating, Ventilating and Cooling greenhouses" ANSI/ASAE EP, 406.4

ASHRAE, (2005) "Handbook of Fundamentals" American Society of Heating, Refrigerating and Air Conditioning Engineers, New York, USA

Baille, A. (1999) "Greenhouse structure and equipment for improving crop production in mild winter climates" Acta Horticulturae, 491: 37-47

Bailey, B. J. (1995) "Greenhouse climate control-new challenges" ActaHorticulturae. 399, 13-23.

Elad, Y. Malathrakis, N.E and A.J Dik. (1996) "Biological control of Botrytisincited diseases and powdery mil-dews in greenhouse crops" Crop Protection. 15(3):229-238.

Hanan, J. J. (1970) "Temperature and humidity observation in CSU greenhouse" Color Flower Grower Assoc. Bull 238, 1-4

Katsoulas, N. ; Baille, A. ; and Kittas, C. (2001) "Effect of misting on transpiration and conductance of a greenhouse rose canopy" Agricultural and Forest Meteorology, 106:233-247. 
Kittas, C. ; Bartzanas, T. ; and Jaffrin, A. (2001b) "Greenhouse evaporative cooling: measurements and data analysis" Transactions of the ASAE, 44(3):683-689.

Kittas, C. ; Bartzanas, T. ; and Jaffrin, A. (2003) "Temperature gradient in a partially shaded large greenhouse equipped with evaporative cooling pads" Biosystems Engineering, 85(1):87-94.

Kittas, C. ; Katsoulas, N. ; and Baille, A. (2001a) "Influence of greenhouse ventilation regime on the microclimate and energy portioning of a rose canopy during summer conditions" J. of Agric. Eng. Res., 79 (30:349360.

Montero, J. I. ; and Segal, I. (1993) "Evaporative cooling of greenhouses by fogging combined with natural ventilation and shading" In: Proceedings of the International Workshop on Cooling Systems for Greenhouses Agritech, May 2-6.

Nelson, P. V. (1996) "Greenhouse operation and management" third edition, Prentice-Hall, Inc., New Jersey 07632.

Öztürk, H. H. ; and Başçetinçelik, A. (2003) "Effect of thermal screens on the microclimate and overall heat loss coefficient in plastic tunnel greenhouses" Turk J Agric, 27: 123-134.

Pringer, J. J. ; and Ling, P. P. (2004) "Greenhouse condensation control understanding and using vapour pressure deficit (VPD)" Fact sheet (series) AEX-800. Ohio State University Extension, Columbus, USA.

Sethi, V. P. ; and Sharma, S. K. (2007) " Survey of cooling technologies for worldwide agricultural greenhouse applications" Journal of Solar Energy, 81:1447-1459.

Willits, D. H. (1999) "Constraints and limitation in greenhouse cooling. Challenges for the next decade" In: Proceedings of the ISHS International Symposium on Greenhouse Techniques towards the Third Millennium, September 5-8.

Willits, D. H. ; and Peet, M. M. (1993) "The effect of evaporative cooling on the efficiency of external greenhouse shade cloths" ASAE, Paper No. 93-4042.

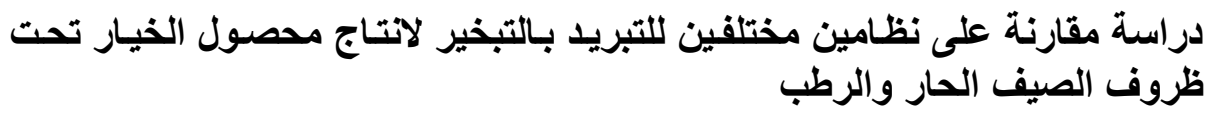


Abdellatif, S. M. et al.

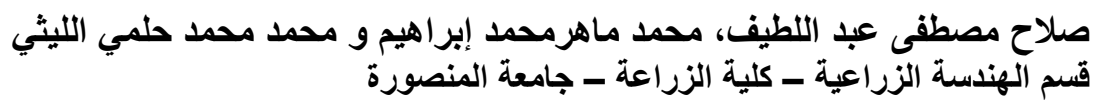

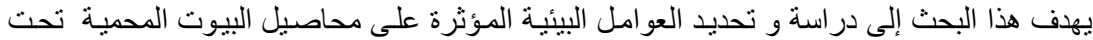

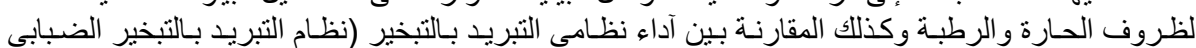

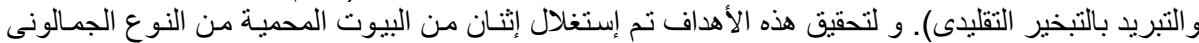



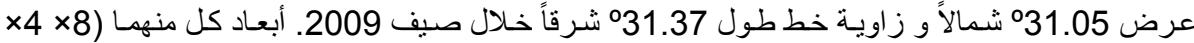

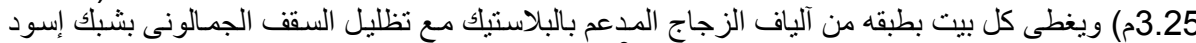

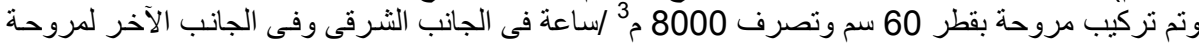

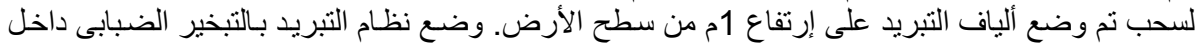

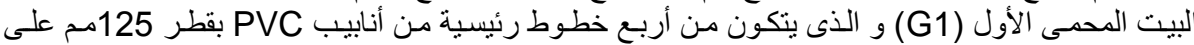

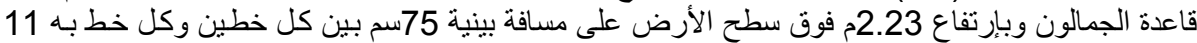

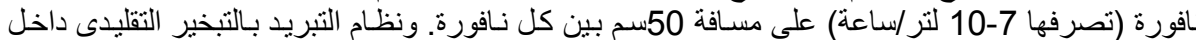

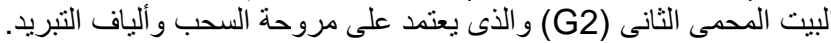

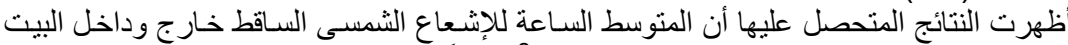
المحمى خـلال فترة التجـارب كانت

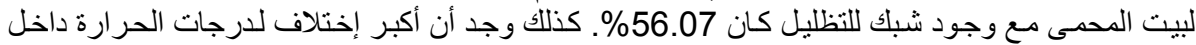

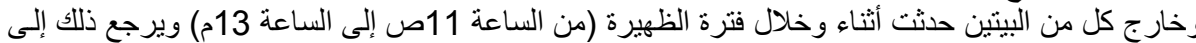

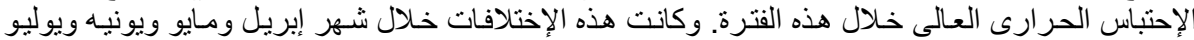

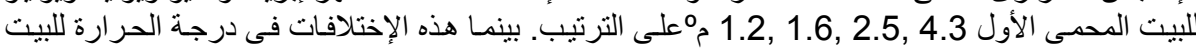

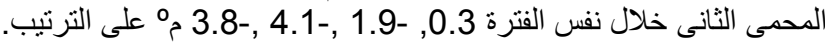

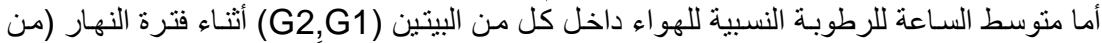

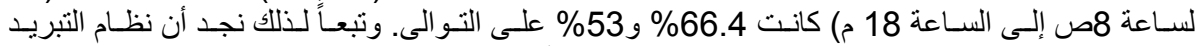

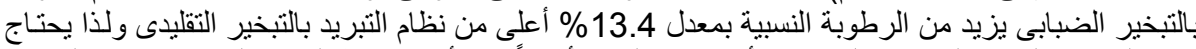

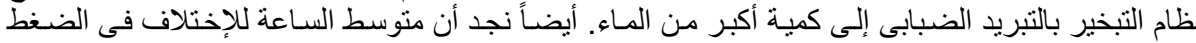

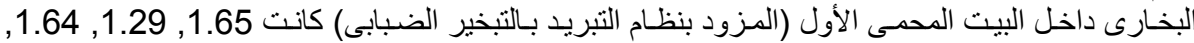

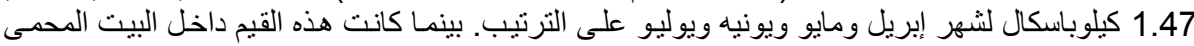

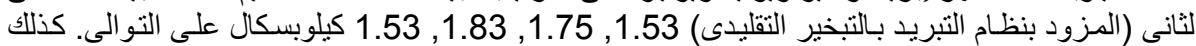

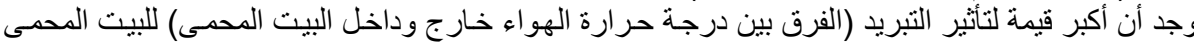

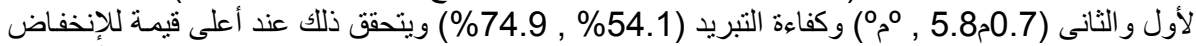

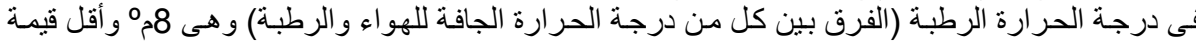

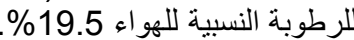

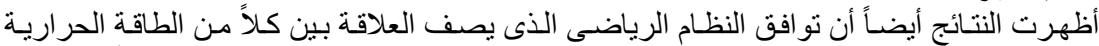

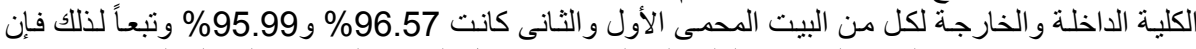

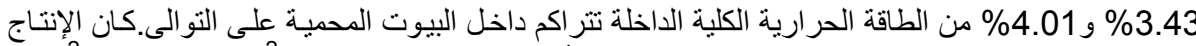

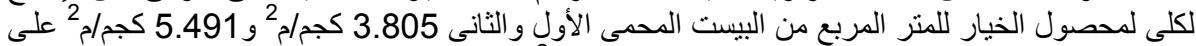



كلية الزراعة - جامعة المنصورة كلية الزراعة - جامعة الزقازيق جامعة
قام بتحكيم البحث

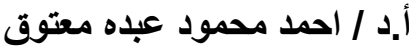

أ.د / محمود عبد الرحمن الثماذلي معتي 